\title{
Live Facial Recognition: Trust and Legitimacy as Predictors of Public Support for Police Use of New Technology
}

Ben Bradford*1, Julia A. Yesberg ${ }^{1}$, Jonathan Jackson ${ }^{2}$ and Paul Dawson

${ }^{1}$ Jill Dando Institute of Security and Crime Science, University College London, UK

${ }^{2}$ London School of Economics and Political Science, UK; and University of Sydney Law School, Australia

${ }^{3}$ Mayors Office for Policing and Crime, London, UK

Ben Bradford, Institute for Global City Policing, Jill Dando Institute of Security and Crime Science, 35 Tavistock Square, London WC1H 9EZ, United Kingdom, ben.bradford@ucl.ac.uk

\begin{abstract}
Facial recognition technology is just one of a suite of new digital tools police and other security providers around the world are adopting in an effort to function more safely and efficiently. This paper reports results from a major new London-based study exploring public responses to Live Facial Recognition (LFR): a technology that enables police to carry out real-time automated identity checks in public spaces. We find that public trust and legitimacy are important factors predicting acceptance or rejection of LFR. Crucially, trust and particularly legitimacy may serve to alleviate privacy concerns about police use of this technology. In an era where police use of new digital technologies is only likely to increase, these findings have important implications for police-public relations and how the "public voice' is fed into debates.
\end{abstract}

Keywords: police technologies; live facial recognition; trust; legitimacy; privacy; worry about crime

Acknowledgements: The survey used in this paper was commissioned by the London Policing Ethics Panel and funded by MOPAC. The chair and members of LPEP were closely involved in setting the aims for the survey and design of some of the survey items used. The views in this paper are those of the authors, however, and do not represent the views of either MOPAC or LPEP. 
Police and other security providers in countries across the world are increasingly turning to new technologies in an effort to undertake core functions more safely and efficiently, and to address a rapidly changing landscape of threats, harms and challenges. Physical technologies like Body Worn Video (BWV), drones, GPS and enhanced scanning equipment are being used more and more alongside - and in conjunction with - software such as 'predictive policing' algorithms and 'big data' in ways that seem to herald a radical shift in the way policing is done (see among many others Ariel et al. 2018; Louis et al. 2019; Meijer and Wessels 2019, Ridgeway 2019). The use of these technologies may shape the relationship between police and public in a variety of different ways, yet in many cases these developments have occurred without significant public discord, or even debate. Is this a result of widespread support of police use of such novel technologies, driven perhaps by trust and institutional legitimacy and/or anxiety about crime? Does the lack of debate spring from resigned acceptance in the face of rapid technological change across society, or a simple lack of knowledge and awareness of the issues? Surprisingly little is known about these questions.

In this paper we report results from a major new London-based study exploring public responses to Live Facial Recognition (LFR) which, unlike some of the other examples above, has been the subject of significant debate. Like automated number plate recognition (ANPR) and related technology, LFR provides a mobile platform for police to generate, analyse and act on 'matches' between automatically captured personal data (i.e. facial images) and records stored in a database- to conduct, that is, automated identity checks in public spaces in real time. Use of LFR by police in the UK is still in its infancy and, at the time of writing, has generated some controversy (see, for example, BBC 2018). The context for the current study was a series of trials conducted by the Metropolitan Police Service (MPS) between 2016 and 2019 (LPEP 2019). In these trials, fixed cameras were deployed to scan the faces of people walking past. Captured images were automatically checked against facial images on a 'bespoke' watch-list: a list of people wanted by the police, drawn up specifically for the operation. Potential matches were flagged for human action, which involved a nominated police officer conducting a visual assessment. Only images flagged as a match were retained-all others were deleted after comparison with the watch-list.

We draw on data from a representative survey of Londoners conducted in 2018 designed to assess how people think about police use of LFR. After being provided with a vignette describing the MPS trialling of LFR, research participants were asked about their concerns (or lack thereof) regarding privacy and whether they thought it was acceptable or unacceptable for the MPS to use LFR. We report levels of support for LFR and privacy concerns, but we also explore three sets of factors that may act jointly or separately to motivate backing for technology such as LFR.

We consider, first, those worried about crime, who may support in a more or less instrumental sense uptake of a technology presented as enhancing the ability of police to apprehend offenders, trading concerns about privacy against concerns about victimisation risk. Second, we draw on research suggesting that when asked to think about the acceptability of new technologies in non-policing arenas, people use heuristics (cognitively based shortcuts that are used to accomplish something that would otherwise take in-depth and/or elaborate mental processing) to help inform views and decisions in situations where they have little knowledge and experience of the issues involved (e.g. Merk and Pönitzsch 2017; Midden and Huijts 2009; Siegrist et al 2007). We test whether trust and legitimacy work as two heuristics through which people make sense of LFR, increasing their willingness to accept its use. Third, and in some contrast, we consider concerns about the privacy implications of LFR, which may place limits around such willingness. Naturally, each of these potential predictors of support are likely to correlate with one another, and we explore the relationships between these explanatory variables, as well as their association with the ultimate response variable: judgements about the acceptability of police use of LFR.

The paper proceeds as follows. After providing a brief overview of LFR technology, we set out our theoretical model for understanding public acceptance, or otherwise, of LFR and present the main hypotheses guiding our analysis. We then outline the methods and data used in this study before proceeding with the results and discussion. We conclude by discussing what the findings mean for police-community relations in an era where police use of novel technologies is only likely to increase.

\section{Live Facial Recognition technology and police use of personal data}


Police capture and use of personal data is by no means a new phenomenon. People living in the UK are already accustomed to the widespread police use of closed circuit video recording (CCTV), automated number plate recognition (ANPR) and, increasingly, body worn video (BWV). Yet, while LFR shares some features with these technologies it is in many respects quite different. In addition to significantly enhanced data matching, LFR relies on biometric processing which provides police with more powerful capabilities (Fussey and Murray 2019). For example, unlike CCTV, LFR partially automates the process of identifying and tracking individuals through their facial features (LPEP 2019) - it uses real time biometric processing of video imagery in order to identify particular individuals. And, unlike ANPR, the 'object' being identified is not disposable or transferable, but the characteristics of a person's face.

Between 2016 and 2019, the MPS conducted a total of 10 test deployments of LFR at various locations and events around London (e.g. Notting Hill Carnival, Stratford shopping mall, Leicester Square). During deployments, LFR software biometrically processes images obtained by fixed cameras in real time. The software identifies any faces in the captured images, creates a digital signature of any identified faces, and then analyses those signatures against a watchlist, which in the case of the MPS trials mostly comprised individuals wanted for various offences. Any potential matches (based on a percentage of corresponding features) result in an alert which displays the image captured by the LFR system alongside the image from the watchlist, to enable a police officer to make a visual comparison. According to the MPS, images that do not result in a match are discarded immediately after processing, while those that do generate a match are retained for 30 days (Fussey and Murray 2019).

The use of LFR by the MPS has generated significant controversy, most notably surrounding: the legal basis for police use of LFR; the human rights implications (e.g. the right to a private life and to freedom of expression); and potential bias and discrimination (e.g. that facial recognition algorithms often disproportionately misidentify minority ethnic groups and women) (Big Brother Watch 2018, Fussey and Murray 2019). Another important consideration is the absence of any significant public debate or consultation during the development of the use of this technology. Very little is known about what the British public think about LFR, and whether - and to what extent - people support police use of this technology. Here we report on the first in-depth study of public attitudes toward LFR.

\section{Trust, legitimacy and empowering police}

There are a number of ways of thinking about what police uptake and use of new technologies 'means' in cultural, social, political and legal terms. We consider here the lay (i.e. public) perspective. We start from the assumption that supporting or agreeing to the use of LFR is in an important sense to empower police - to positively accept a development that grants the police more power, which comes along with an acceptance of risk that this power may be misused. In the current case, this relates primarily to an enhanced ability to intrude into the privacy of individuals as they use public and quasi-public spaces, by capturing their physical appearance and comparing it to a list of 'wanted' persons.

On what basis, then, might people find this extension of police power acceptable or unacceptable? Although we are interested primarily in the relationship between trust and legitimacy as predictors of support and as factors that may motivate acceptance of developments that enhance the intrusive power of police, we consider three different sets of issues: public trust and/or police legitimacy (as alternative explanations), but also privacy concerns and worry about crime. All have been found to be predictive of public attitudes towards other 'new' policing technologies, such as body worn video (Crow et al. 2017) and drones (Sakiyama et al. 2017; Heen et al. 2018).

Of the three factors listed above the last is relatively simple, and is aligned with a broadly rational choice perspective (although concern about crime clearly also has symbolic meaning and content, Farrall, Jackson and Gray 2009). Here, those who are concerned about crime are more likely to judge developments such as LFR positively, and/or be more accepting of them, at least to the extent that they believe they will make 'fighting crime' easier and more effective.

Yet, the judgements people make of police, perhaps particularly across dimensions of trust and legitimacy, also seem likely to influence the extent to which they find LFR acceptable. In research on public acceptance of new technologies in non-policing arenas the 'affect heuristic' (Slovic et al 2002; 2004) suggests that emotional responses to new developments, and the organisations and institutions implementing them, can be central in shaping people's assessments of the associated risks and benefits, and hence their willingness to support or oppose the introduction or uptake of, for example, gene- 
splicing, nanotechnology, or novel power-generating technology. Trust comprises a second and closely related heuristic, in that affective responses to a particular issue are formed in the context of trust, or distrust, in the actors concerned (c.f. Yesberg and Bradford 2018). It is well established that trust informs people's willingness to accept police presence, action and authority to dictate appropriate behaviour (Jackson and Bradford 2010; Sunshine and Tyler 2003; Tyler 2013; Tyler and Huo 2002).

We consider the idea that trust in the police operates as a heuristic through which people infer that LFR does not represent a threat to them, and is therefore an appropriate tool for the police to use. Trust motivates acceptance of police use of LFR, we propose, because it provides reassurance that this new power will be used in the correct way and not be abused. Indeed, at the core of the concept of trust is a willingness to accept vulnerability in relation to the trust object (PytlikZillig and Kimbrough 2015). To place trust is to willingly accept the risk that the trust object may abuse their position and act in ways that are not aligned with one's own interests.

Trust therefore constitutes positive expectations about how officers will (and do) behave under conditions of uncertainty; it references assessments of a particular police action (i.e. the use of LFR) and acceptance of the risks involved because the assumed intentions and capabilities of officers are assessed positively. Focusing on the cognitive rather than the affective or behavioural components of trust, we differentiate between (a) trust in police procedural fairness and responding to community needs and (b) trust in police effectiveness. We test which is most important-is it about effectively dealing with crime (i.e. attitudes towards the trustworthiness of the police to prevent terrorism, respond to emergencies, and provide a visible patrolling presence) or is it about being trustworthy to treat people fairly and listen/respond to people's concerns? Or is it a bit of both?

In studies of public acceptance of new technologies in non-policing arenas it makes sense to only focus on trust in the actors involved (e.g. scientists). Given the unusual regulatory powers vested in the police, however, legitimacy is a second significant concept and may also shape public responses to police use of LFR. Legitimacy is the normative justification of power (normative alignment with the police) that motivates an internalised acceptance of rightful authority (duty to obey the police) among those same citizens. Normative alignment connects the principled justification of power to societal expectations regarding what constitutes legitimate practice; to feel normatively aligned with the police is to believe that officers wield their authority in ways that accord with societal expectations about appropriate group conduct (Jackson et al 2013; Tyler and Jackson 2014; Bradford and Jackson 2018). People who grant legitimacy accept the right of the police to enforce the law and dictate appropriate behaviour - their own as well as that of others. In other words, legitimacy involves empowering the police, granting them the right to determine what is appropriate and acceptable.

Legitimacy may also, in addition to trust, operate as a heuristic through which people judge that the police have the right to expand their scope of powers as they see fit; in this particular instance, to use LFR. As with the two components of trust, we assess the extent to which normative alignment is a predictor of privacy concerns and acceptance of LFR, adjusting for duty to obey, and vice versa. Prior work has found that believing the police are a proper and just institution encourages support for actions that fall within existing normative boundaries of behaviour (Gerber and Jackson 2017; Bradford, Milani and Jackson 2017). Believing that power is exercised appropriately is to believe that power is rightfully held, because the ends to which it is directed are appropriate.

In the current context, it may be that believing the police generally use their power in normatively appropriate ways leads people to assume that police have picked this new power because it is appropriate (in essence, an argument that 'they generally do the right thing, so why would this be any different?'). Moreover, when people believe police behave in appropriate ways, act with the right intentions, and have the best interests of the policed at heart this seems likely to generate, or indeed simply is, positive affect: a sense that police are morally or in some other way 'good' (Midden and Huijts 2009), and therefore that they are acting in an appropriate and acceptable way - in our case, in relation to use of a novel technology.

If normative alignment is an active recognition of the right of police to expand their powers, based on the starting belief that they exercise their current powers appropriately, duty to obey is a more passive recognition based on deference to the judgement of the police. While normative alignment consists of the positive authorization of police actions, duty to obey indicates mere acceptance of the right of police to act in certain ways - one allows the police the right to determine what it is best to do. If duty to obey is a positive predictor of acceptance of LFR, therefore, this plausibly reflects a kind of 
deference to power, where one cedes the right of the police to decide what powers are appropriate and how they should be used.

Trust and legitimacy are closely associated with one another. Most recent studies have proposed that the cognitive elements of trust are a source of legitimacy. When people believe the police are competent, fair and engaged with the communities they serve, this indicates they are behaving as they should - i.e. in line with normative expectations - thus generating a sense of normative alignment and corresponding duty toward them (Huq, Jackson and Trinkner 2017; Trinkner, Jackson and Tyler 2018). This raises two connected possibilities. First, legitimacy judgements may mediate, partially or fully, any relationship between trust and, in the current case, assessments of the acceptability of LFR. Second, in previous studies that have shown that trust predicts acceptance of police powers and abilities but that did not include measures of legitimacy (e.g. Yesberg and Bradford 2018), trust may have been standing as a partial or full proxy for legitimacy. If this is indeed the case, then it would alter our understanding of why people support or oppose granting new powers to the police by shifting the emphasis from trust to legitimacy as the central heuristic. In the current study, we test whether any association between trust and judgements about LFR is mediated by legitimacy.

The third set of factors that might affect reactions to police use of LFR is privacy concerns. Such concerns are, of course, central to the debate that has developed around LFR: "Live automated facial recognition cameras, acting as biometric identification checkpoints, are a clear threat to both individual privacy and privacy as a social norm" (Big Brother Watch 2018: 13). Judgements about the acceptability of police use of LFR seem almost certain to be influenced by assessments of the extent to which such use violates rights to privacy and a desire for anonymity, perhaps particularly from the state.

However, it seems equally clear that privacy concerns may themselves be influenced by trust and legitimacy judgements. This follows directly from the argument above-to the extent that an individual trusts police (believes them to be competent and well-intentioned) and/or legitimises them (grants them the right to determine appropriate actions) privacy concerns will be allayed. Conversely, if trust and legitimacy are low or absent, privacy concerns will be accentuated precisely because the fear of inappropriate intrusion will be more salient. We might therefore expect any associations between trust and/or legitimacy and acceptance of LFR to be mediated by privacy concerns.

Building on the discussion above, the theoretical model presented in Figure 1 guides the analysis that follows. Here, legitimacy is shaped by trust (and worry about crime), while all three constructs have effects on privacy concerns and acceptance of LFR. Legitimacy and privacy concerns also have mediating roles. This is, of course, just one way of conceptualising the relationships involved - to give one example, worry about crime could affect trust as well as legitimacy. As always in such cases we merely select a model that allows us to easily and clearly investigate the key questions at hand; specifically, to test the following six hypotheses:

H1: Worry about crime will be positively correlated with judgements about LFR acceptability.

$\mathrm{H} 2$ : Those who trust the police more - across dimensions of effectiveness, fairness and community engagement - will be more likely to find police use of LFR acceptable.

H3: Those who grant the police more legitimacy - as normative alignment and/or duty to obey - will be more likely to find police use of LFR acceptable.

H4: Those with greater concerns about privacy will be less likely to find police use of LFR acceptable.

H5: Legitimacy judgements will mediate some or all of the association between trust and LFR acceptability.

H6: Privacy concerns will mediate some or all of the association between trust, legitimacy and LFR acceptability.

[Figure 1 near here]

Data and Methods

Data 
This study draws on survey data of 1,092 Londoners fielded between 23 May and 4 June 2018 on behalf of the London Policing Ethics Panel. ${ }^{1}$ The survey captured participants' views on the ways the MPS gathers and retains personal data, primarily in relation to Live Facial Recognition (LFR), along with more general perceptions of police use of personal data. Respondents were identified using YouGov's Omnibus: a UK panel of $800,000+$ individuals who have agreed to take part in surveys. Panellists received an e-mail inviting them to take part in a survey. The responding sample was weighted to provide a representative sample of the London adult population (see Table 2 for the structure of the sample), although only the descriptive statistics shown below are presented on a weighted basis.

\section{Constructs and measures}

Two measures of 'LFR acceptability' are used in the analysis that follow, comprising the ultimate response variables in the models estimated. The first is a binary indicator formed from a survey item that asked "Do you think it is acceptable or unacceptable for the Met Police to use LFR?", with simple yes/no response categories (see Table 1). The second is an additive scale constructed from eight survey items probing the acceptability of LFR across a range of scenarios: in a train station or at a major ticketed event and in relation to people wanted for terrorism, serious violent crime, minor crimes, and disorder (see Table 3). These items were originally on 5-point agree/disagree scales and for the purposes of the current paper they were dichotomised and summed to construct a 9-point scale (mean $=5.3$; SD $=2.7$ ), where higher scores indicate greater acceptance of the use of LFR across different scenarios. ${ }^{2}$

Six additional constructs are used to test the hypotheses laid out above: worry about crime; trust in police fairness, effectiveness and community engagement; normative alignment; duty to obey; and privacy concerns. All are represented by latent variables derived and validated via Confirmatory Factor Analysis (CFA) in the statistical package Mplus. Observed variables were all measured on Likert-type response scales; these were set to ordinal for the CFA, and full information maximum likelihood estimation was used, meaning that cases with some missing values were retained in the analysis (this reduced the sample size by 10 to 1,082 ). Item wordings, factor loadings and item $\mathrm{R}^{2}$ values are shown in Appendix Table 1. Model fit is satisfactory according to the approximate fit statistics, and we proceed with these six measures.

Three elements of the CFA model are worthy of comment. First, note that trust in police fairness and community engagement is represented by a combined measure - this is partly due to space constraints in the survey and partly because previous work has shown these two different 'components' of trust to be very highly correlated with one another (Jackson et al 2013). Second, the worry about crime factor is dominated by the measure relating to local crime and anti-social behaviour, which has a far higher factor loading and $\mathrm{R}^{2}$ value than the measure of worry about terrorism. However, we decided to proceed with both observed indicators as (a) one would expect local concerns to be dominant in most people's minds (Farrall et al 2009) but also (b) in the case of LFR a more abstract concern about terrorism may also play a role, and representing both together is more parsimonious than treating them separately. Note also that the items measuring privacy concerns, and therefore the factor extracted, are coded such that high equals less concern.

Finally, we add an important control variable to the analysis - political ideology. While studies of trust and legitimacy in policing contexts have tended to ignore this issue (for exceptions see Roché and Roux 2017, Yesberg and Bradford 2018), it is plain that ideological orientation, particularly along the libertarian-authoritarian axis, may be an important factor affecting people's response to technologies such as LFR. While we only have a 'rough-and-ready' approximation to such attitudes available for the current study, the 'traditional' 7-point left-right scale ("On a scale of 1 to 7 where $1=$ completely on the left and 7=completely on the right, where would you place yourself politically?"), we believe it is

\footnotetext{
${ }^{1}$ The London Policing Ethic's Panel is an independent panel set up by the Mayor of London to provide ethical advice on policing issues. UCL and the Mayor's Office for Policing And Crime commissioned the survey as part of the Panel's wider investigation into the MPS's use of LFR.

${ }^{2}$ This variable was entered into the final model as an observed indicator. We followed this approach to ensure maximum comparability across the two SEMs shown in Figures 2 and 3 (i.e. that the measurement models would be the same in both cases). Further analysis suggested the eight items used in the acceptability scale all loaded very strongly onto one factor, which was highly correlated with the sum score actually used $(\mathrm{r} \approx .9)$.
} 
nonetheless a useful measure to include in the analysis. Appendix Table 2 shows the correlation matrix for this and the other continuous variables used in the analysis.

\section{Results \\ Acceptability of Live Facial Recognition}

To measure the acceptability of LFR, respondents were provided with a vignette describing the technology (see below) before being asked to make judgements about it. This had two purposes. First, it was important to ensure that all respondents were clear about what was actually under discussion, something that could not be assumed even given the extensive media coverage of the MPS trials. Second, a 50:50 'split ballot' approach was implemented wherein respondents were randomly assigned to one of two different vignette conditions. Half read a vignette which informed them that LFR images are discarded once matched against a watch list. The other half of respondents read an otherwise identical vignette that informed them images could be kept for future use. This experimental manipulation was designed to measure the extent to which people make a distinction between the retention or not of images: one of the key issues in the use of LFR technology.

'Discard' vignette - The Metropolitan Police Service is currently trialling the use of Automated Facial Recognition $(A F R)^{3}$ software which could be used to apprehend people who are of interest to the police. The technology involves the use of cameras at specific public events which scan the faces of those passing by and flag up potential matches against a 'watch-list' of images of individuals of interest to the police (e.g. those with an outstanding arrest warrant). Only images that come up as a match on the watch-list are retained by police; images of people not on the list are immediately discarded.

'Keep' vignette - The Metropolitan Police Service is currently trialling the use of Automated Facial Recognition (AFR) software which could be used to apprehend people who are of interest to the police. The technology involves the use of cameras at specific public events which scan the faces of those passing by and flag up potential matches against a 'watch-list' of images of individuals of interest to the police (e.g. those with an outstanding arrest warrant). These images, including those of people not of interest to the police at the time, could potentially be retained for use in future investigations, for example to reconstruct the movements of a person suspected of a crime.

After reading the vignettes, respondents were asked a series of questions probing their views on police use of this technology and whether, overall, they thought this to be acceptable. Due to the random assignment to each vignette, we can be confident that any difference in views on LFR across the two groups of respondents was due to the experimental manipulation. Yet, despite this being one of the central ethical issues in the use of LFR technology - is a permanent police record of the presence of innocent people at a particular place and time being created (LPEP 2019)—respondents drew no distinction between the two examples. Table 1 shows that $58 \%$ in the 'discard' condition thought police use of LFR was acceptable, compared with $56 \%$ in the 'retain' condition, a statistically non-significant difference. Similarly, across all the other items shown in the table, which represent more specific views about police use of this technology, responses did not differ significantly (or substantively) between the discard and retain groups.

[Table 1 near here]

Given that manipulation of the vignettes did not appear to have any significant effect on respondents' views, we pooled respondents from the two conditions and proceeded with analysis using the full sample. The final item shown in Table 3 comprises the first measure of acceptability described above: while a majority of respondents indicated acceptance of LFR this was by no means overwhelming, indicating this is an area of policy open to public contest and debate.

Keeping focus on the measure of overall acceptability, Table 2 shows that there was some significant variation in views across different socio-demographic categories. Older people were more likely than younger people to judge police use of LFR acceptable, and white people were more likely

\footnotetext{
${ }^{3}$ Note the change of name-at the time the survey was fielded, there was some confusion over the terminology surrounding the technology being trialled by the MPS. The correct term is Live Facial Recognition; however, respondents were informed about Automated Facial Recognition technology in the vignettes and throughout the survey. Aside from the vignettes presented here, to avoid confusion, we use the term LFR throughout this paper.
} 
to do so than people from most other ethnic groups. However there was little variation in views by gender, country of birth, social class or crime victimisation,

[Table 2 near here]

Table 3 shows results relating to the acceptability of police use of LFR in more specific scenarios (i.e. the items used to construct the second measure of acceptability described above). Support was much higher when respondents were told LFR was to be used to identify potential terrorists or those wanted for serious violent crimes, but, by contrast, support in relation to minor crimes and nuisance behaviour was much lower, indeed even lower than in the general case shown in Tables 1 and 2. Notably, respondents did not distinguish between the two sites mentioned in the scenarios. In other words, they did not think about police use of this technology any differently when the site was a privately-owned space (ticketed event) or what is in effect a public space, or at least somewhere where many people using it have little choice to do otherwise (train station).

[Table 3 here]

The results displayed in Table 3 support our decision to use two measures of acceptability in our analysis. The way respondents thought about police use of LFR clearly (a) changed as a result of being prompted to think about specific scenarios and (b) exists on a continuum, with much greater support for some uses compared with others.

\section{Predicting judgements about LFR acceptability}

To test the hypotheses proposed above we used structural equation modelling (SEM), again in Mplus. SEM is a particularly suitable technique in the current context because it allows us to simultaneously estimate all paths and hypothesized mediation effects show in Figure 1 above. Results from the first model, with the binary measure of acceptability, are shown in Figure 2. Here, legitimacy judgements were regressed on trust, worry about crime and political orientation; privacy concerns were regressed on legitimacy, trust, worry about crime and political orientation; and LFR acceptability was regressed on all other variables. Only paths significant at the 5\% level are shown in the figure.

[Figure 2 here]

Starting from the left hand side, we find first that both normative alignment and duty to obey are positively and strongly predicted by trust in fairness and community engagement; net of this, there is no correlation between trust in police effectiveness and legitimacy. Second, worry about crime and political orientation both have weaker but still significant partial associations with legitimacy - those more worried about crime, and who placed themselves further to the right politically, tended to grant the police more legitimacy.

Third, both components of legitimacy are positively correlated with privacy concerns, with the statistical effect of normative alignment twice that of duty to obey ( $\beta=.52$ compared with .22$)$. People who granted the police more legitimacy were less concerned about the privacy implications of LFR. Fourth, people on the left politically tended to have greater privacy concerns. Fifth, controlling for the other variables in the model the association between trust in fairness and engagement and privacy concerns is negative (i.e. those with higher levels of trust tended to have greater privacy concerns). This apparently contradictory finding can be construed as an artefact of the model: the pairwise correlation between these two variables was positive $(r=.20)$ (see Appendix Table 2). In other words, it is only when holding constant the other variables in the model that the negative association emerges.

Sixth, and crucially, privacy concerns and LFR acceptability are very strongly associated $(\beta=.79)$; indeed, they almost collapse into one another. To have privacy concerns about LFR is almost automatically to find it unacceptable, although not entirely so. Finally, privacy concerns fully mediate the associations between all other explanatory variables and LFR acceptability. In turn, legitimacy judgements fully mediate the association between trust and worry about crime and privacy concerns (with the exception of the anomalous direct path from fairness/engagement). There is however a significant direct path from political orientation to privacy.

Table 4 shows the direct, indirect and total statistical effects of worry about crime, trust and legitimacy on LFR acceptance. The total effects of worry about crime and trust in fairness/engagement are positive but entirely mediated by legitimacy judgements and privacy concerns (further analysis suggested that in both cases the most important pathway ran through normative alignment). Effects decomposition also shows that the indirect effect of normative alignment on acceptance via privacy concerns was twice that of duty to obey $(\beta=.42$ compared with .22$)$; normative alignment thus emerges 
as the most important component of legitimacy in terms of motivating support for police use of this novel technology.

[Table 4 near here]

Figure 3 repeats the SEM analysis, this time with the sum score measure of acceptability as the ultimate response variable: recall that higher scores on this measure indicate greater support for more uses of LFR. Strikingly, this model suggests that the predictors of acceptability, measured thus, are almost identical to those shown in Figure 2 above. As before, all the association between trust and worry about crime, and acceptability, is mediated by legitimacy and privacy concerns (and the indirect statistical effect of trust in fairness/engagement on acceptance, for example, remains significant, $\beta=.25$, $\mathrm{p}<.0005)$. The statistical effect of duty to obey on acceptability is likewise fully mediated by privacy concerns (indirect effect $\beta=.10, \mathrm{p}=.002$ ).

[Figure 3 here]

There are three differences from the previous model, however. First, the association between privacy concerns and acceptance is much lower $(B=.42$ compared with $B=.79)$. Second, there is a statistically significant direct path from normative alignment to acceptance. Partially as a result of this, the total effect of normative alignment on acceptance in this model is $\beta=.46$, almost identical to the total in the binary acceptability model $(\beta=.42)$. Third, there is a statistically significant direct path from worry about crime to acceptance.

The most important difference between the models using the two different measures of acceptability is therefore the weaker (although still robust) association between privacy concerns and acceptability in the second model. One interpretation of this may be that when people are prompted to think about specific crimes and those 'wanted' for them, particularly terrorism and violent crime, privacy concerns become relatively less important for many because they cannot imagine themselves being caught up in such events (or being 'confused' with a terrorist). This argument appears supported by the fact that there is now a direct path from worry about crime to acceptance, further suggesting crime was a more salient issue to respondents when answering the scenario-based acceptability items. Despite all this, however, the basic association between trust and legitimacy, and acceptance of police use of LFR technology, remains almost unchanged from the previous model.

\section{Discussion}

To return to the six hypotheses that motivated our analysis, we first found support for H1: people worried about crime tended to be more accepting of police use of LFR. We also found support for H2, in that people who trusted more in police fairness and community engagement were more accepting; net of this association, though, there was no significant statistical effect of trust in police effectiveness on acceptance. By contrast, both dimensions of legitimacy were associated with acceptance, albeit that normative alignment seemed to be the most important. H3 was therefore also supported. Legitimacy also mediated all of the modelled association between trust and acceptance (H5).

Privacy concerns had by some margin the strongest association with acceptance (H4). Indeed, in the first SEM to have strong concerns over privacy was almost inevitably to reject the technology, and vice versa, although this association was attenuated in the second SEM using the scenario-based measure of acceptability. Finally, privacy concerns largely mediated the association between legitimacy (and trust) and LFR acceptance (H6).

Taken together, these results present a compelling picture. The primary factor motivating acceptance or rejection of police use of LFR is privacy concerns - the sense that this technology may be used to intrude into people's lives. Yet, such concerns are powerfully shaped by legitimacy, particularly across the dimension of normative alignment. Individuals who felt police shared their norms and values were considerably less likely to be worried about the privacy implications of LFR. Similarly, albeit to a less extent, those who felt a sense of duty to obey police-who accepted the ability of police to make enforceable decisions-were also less concerned about privacy. The indirect statistical effects of trust and worry about crime on acceptance, while still significant, were more distant, in that these were fully mediated by legitimacy. Notably, people who trusted police more were more accepting of LFR, but only because they granted police more legitimacy.

Our findings are broadly in line with other research on public support for police use of new technologies, while also, we think, bringing some conceptual clarity to the debate. Crow and colleagues (Crow et al. 2017), for example, found that perceptions of police performance (an aspect of trust) and 
privacy concerns predicted views of the 'benefits' of police body worn cameras (as measured by questions such as "Body-worn cameras will improve police officer behaviour during interactions with residents" - ibid, Table 2). Miethe et al. (2019) report that views of police procedural justice, another aspect of trust, predicted support for body worn cameras across a range of use scenarios, although conditioning on procedural justice there was little association between legitimacy (measured as a mixture of trust, perceived duty to obey and value alignment) and support. By contrast Heen et al. (2018) found that legitimacy (measured as a combination of trust and perceived duty to obey) was associated with views about police use of drones, while Sakiyama et al. (2017) found that privacy concerns were a strong predictor of support for the use of drones.

To return to the central theoretical puzzle animating our study, then, it seems that legitimacy provides a stronger and more proximate heuristic than trust, at least when people are thinking about police use of a novel technology such as LFR. There are a number of mutually compatible interpretations of this finding. First, because legitimacy as normative alignment involves ceding power to police based on a sense that they operate according to a shared moral framework - that they will try to do the right thing - this may alleviate concerns about privacy and therefore promote acceptance. Second, legitimacy as duty to obey may involve passive acceptance, which not so much alleviates privacy concerns as obviates them, rendering them superfluous to attitude formation and decision making. Third, to return to the idea of the affect heuristic, to believe that police are 'morally similar' to oneself is in an almost definitional sense to have positive affect toward them. Legitimacy may therefore promote a positive emotional response to developments such as LFR, again alleviating concerns about privacy.

Whichever combination of these factors is in play, all this suggests that legitimacy and not trust is the central factor animating public acceptance, or rejection, of changes to police powers and technological abilities. While trust-which we have measured as positive expectations and evaluations of the abilities and benevolence of police-does play a role, it only does so because it is linked to legitimacy. At stake seems not to be more specific judgements about the abilities and intentions of police - i.e. to use new technologies in an appropriate way - but rather a more general sense that they operate according to an appropriate moral framework and are therefore worthy of, indeed there is a duty to, support and empower them. This sense deadens or circumvents any concerns that a power might be used improperly, something represented in the current context by concerns over privacy. Future studies that consider why people support change in policing should therefore include measures of legitimacy, not least to investigate whether our findings replicate across different policies and powers in the current rapidly changing police environment.

\section{Limitations of this study}

The study above suffers, of course, from a number of limitations. First and most obviously, we cannot estimate causal effects from our cross-sectional data - all we have shown is that trust, legitimacy and other variables are correlated with people's acceptance of LFR. Second, we have no direct measure of affect so we cannot test whether acceptance of LFR is influenced by people's emotional response to this development (Slovic et al 2002; 2004). Trust, however, is a closely related heuristic to affect, and people's affective response to LFR is also likely to be very highly correlated with legitimacy and privacy concerns, so adding direct measures of affect may not have added much to the analysis. Third, although we have measures of trust in police fairness and engagement, and in police effectiveness, we have no measure of trust as acceptance of vulnerability. The notion that a willingness to accept vulnerability lies at the heart of trust is increasingly well accepted in the literature on this topic (PytlikZillig and Kimbrough 2015), and including this measure of trust may have altered our findings somewhat.

\section{Conclusion}

LFR technology has proven to be one of the more politically contentious issues in policing in recent years, generating significant press and public debate and at least two legal challenges. Results from the study presented here seem to support the idea that this is an area of significant disagreement: when presented with a basic question about whether it was acceptable for police to use LFR, respondents split almost 50/50. We demonstrated above that public trust and particularly police legitimacy were important factors shaping acceptance or rejection of this policing technology. Crucially, this is because 
legitimacy, in particular, served to allay, deaden or possibly simply circumvent privacy concerns. To put it another way and reverse the formulations presented above, people who trust the police less, and who grant less legitimacy, tend to have heightened concerns about privacy, and such concerns are very strongly associated with a view that it is not acceptable for police to use LFR. Interestingly, although perhaps not surprisingly, judgements about the police are much more important predictors of acceptance than concerns about crime, suggesting that an affective link - or its absence - with those using the technology (i.e. police) is more important than the ends toward which it is oriented.

We close with some thoughts on what this means for police-public relations in an era where police use of novel technologies is only likely to increase. On the one hand, the lesson here is clear. If police and policy-makers wish to 'take people with them' as they push for extras powers and technological abilities, then developing and sustaining trust and legitimacy will be of central importance. One interesting implication of the findings presented above is that because direct and vicarious encounters with individual officers have strong effects on attitudes, positive or negative, towards police (Jackson et al 2013, Bradford et al 2009), the mundane activity of everyday police work ('low' policing, Brodeur 2010) can have important implications for the public acceptance or rejection of novel technologies working more towards the 'high' end of policing. Yet we would also point to the importance of engaging with the wider public on these issues, and devising ways to promote legitimacysustaining dialogues around the uptake and use of tools such as LFR (LPEP 2019).

On the other hand, the apparent importance of trust and legitimacy to people's judgement formation in this area points to important limitations in the extent to which public approval, or disapproval, is a suitable metric by which to judge the appropriateness of police activity. This comes most clearly into focus in our discussion of the effect of legitimacy as duty to obey, above. If it is true that feeling a sense of moral duty to obey police involves a passive acceptance of police activity, then this suggests people are not making an ethical judgement, let alone a legally or politically informed one, but simply ceding to police the ability to act as they wish. Indeed, such 'authorisation' can be seen as central to the concept of legitimacy, at least as it has been theorised by some (e.g. Kelman and Hamilton 1989). Empowering the police based on a sense of normative alignment may have much the same effect, even if the psychological mechanism at play is rather different. Put bluntly, trust and the legitimacy it helps generate may lead some people to support police activity which is objectively troubling, inappropriate, or plain wrong.

Any such concerns should be tempered by the fact that legitimacy is strongly founded in fairness judgements, and there is a wealth of evidence that suggest unfair practice can have significant downstream effects, resulting ultimately in the withdrawal of consent and sometimes radical change. There is moreover an emerging consensus that when making legitimacy judgements people think about whether police activity is occurring within appropriate legal and ethical boundaries, and that legitimacy suffers when such boundaries are transgressed (Trinkner, Jackson and Tyler 2018); relatedly, recent studies have found that legitimacy promotes support for action with normatively appropriate boundaries but not for activity - such as excessive use of force - that breaches them (Bradford et al 2017; Gerber and Jackson 2017). Legitimacy and the processes that sustain it do not, therefore, provide carte blanche, but rather exist in dynamic tension with police activities and policies, sometimes providing support, at other times constituting a brake or causing a change of direction.

Nevertheless, the extent to which trust and legitimacy give police the power to frame debates and press for enhanced powers should not be under-estimated (Harkin 2015). The symbolic power wielded by police (Loader and Mulcahy 2003) grants a significant ability to determine which aims are important and how it is best to achieve them. Indeed, legitimacy as we have described it above is an important constituent component of this symbolic power, and the fact that most people still invest significant legitimacy in the police may explain why campaigns such as that launched by Big Brother Watch (2018) against LFR often fail to gain widespread traction. Although they may not know much about the topic under discussion, large numbers of people are inclined to believe police are probably doing the right thing and are happy to let them get on with it. A somewhat smaller but still significant group - those who grant the police less legitimacy - are conversely inclined to believe they are probably doing the wrong thing, whatever it is, and should stop. The challenge for regulators, and the communities of interest that form around issues such as LFR, is therefore to consider how reasonable it is to expect meaningful public input into decision-making processes, how informed lay opinion needs to be to provide such input, how appropriate information is to be provided, and by whom. 


\section{References}

Ariel, B., Sutherland, A., Henstock, D. et al. (2018), Paradoxical effects of self-awareness of being observed: testing the effect of police body-worn cameras on assaults and aggression against officers', Journal of Experimental Criminology 14(1): 19-47.

BBC (2016). Police Facial Recognition System Faces Legal Challenge. Available from: https://www.bbc.co.uk/news/uk-44928792 [Accessed 16 Sep 2019].

Big Brother Watch (2018). Face Off: The Lawless Growth of Facial Recognition in UK Policing. Available from: https://bigbrotherwatch.org.uk/wp-content/uploads/2018/05/Face-Off-finaldigital-1.pdf [Accessed 16 Sep 2019].

Bradford, B. and Jackson, J. (2018). 'Police Legitimacy among Immigrants in Europe: Institutional Frames and Group Position', European Journal of Criminology, 15/5: 567-588.

Bradford, B., Jackson, J. and Stanko, E. (2009). 'Contact and Confidence: Revisiting the Impact of Public Encounters with the Police', Policing and Society, 19(1): 20-46.

Bradford, B., Milani, J. and Jackson, J. (2017), 'Identity, Legitimacy and "Making Sense" of Police Use of Force', Policing: An International Journal, 40(1): 614-627.

Brodeur, J. P. (2010), The Policing Web. Oxford: Oxford University Press.

Crow, M.S., Snyder, J.A., Critchlow, V.J. and Smykla, J.O. (2017), 'Community Perceptions of Police Body-Worn Cameras: The Impact of Views on Fairness, Fear, Performance, and Privacy', Criminal Justice and Behavior 44(4): 589-610.

Farrall, S. D., Jackson, J. and Gray, E. (2009), Social Order and the Fear of Crime in Contemporary Times. Oxford: Oxford University Press.

Fussey, P. and Murray, D. (2019), Independent Report on the London Metropolitan Police Service's Trial of Live Facial Recognition Technology. Available from: [Accessed 16 Sep 2019].

Gerber, M. M. and Jackson, J. (2017), 'Justifying Violence: Legitimacy, Ideology and Public Support for Police Use of Force', Psychology, Crime \& Law, 23/1: 79-95.

Harkin, D. (2015), 'Police legitimacy, ideology and qualitative methods: A critique of procedural justice theory', Criminology and Criminal Justice 15(5): 594-612.

Heen, M.S.J, Lieberman, J.D. and Miethe, T.D. (2018), 'The thin blue line meets the big blue sky: perceptions of police legitimacy and public attitudes towards aerial drones', Criminal Justice Studies, 31(1): 18-37.

Huq, A., Jackson, J. and Trinkner, R. (2017). 'Legitimating Practices: Revisiting the Predicates of Police Legitimacy', British Journal of Criminology, 57/5: 1101-1122.

Jackson, J. and Bradford, B. (2010), 'What is Trust and Confidence in the Police?', Policing: A Journal of Policy and Practice, 4/3: 241-248.

Jackson, J., Bradford, B., Stanko, B. and Hohl, K. (2013), Just Authority? Trust in the Police in England and Wales. Oxon: Routledge.

Kelman, H. C. and Hamilton, V. L. (1989), Crimes of Obedience. New Haven, CT: Yale University Press.

Loader, I. and Mulcahy, A (2003), Policing and the condition of England. Oxford: Oxford University Press.

London Policing Ethics Panel (2019), Final Report on Live Facial Recognition. Available from:http://www.policingethicspanel.london/uploads/4/4/0/7/44076193/lfr_final_report__may_2019.pdf [Accessed 13 Sep 2019].

Meijer, A. and Wessels, M. (2019) 'Predictive Policing: Review of Benefits and Drawbacks', International Journal of Public Administration, 42(12): 1031-1039.

Miethe, T. D., Lieberman, J. D., Heen, M. S., \& Sousa, W. H. (2019). Public attitudes about body-worn cameras in police work: a national study of the sources of their contextual variability. Criminal Justice Review 44(3): 263-283.

Merk, C. and Pönitzsch, G. (2017), 'The Role of Affect in Attitude Formation Toward New Technologies: The Case of Stratospheric Aerosol Injection', Risk Analysis, 37/12: 2289-2304.

Midden, C. J. and Huijts, N. (2009), 'The Role of Trust in the Affective Evaluation of Novel Risks: The Case of CO2 Storage', Risk analysis, 29/5: 743-751.

PytlikZillig, L. M. and Kimbrough, C. D. (2015), 'Consensus on Conceptualizations and Definitions of Trust: Are We There Yet?’, in E. Shockley, T. M. S. Neal, L.PytlikZillig, and B. Bornstein, 
eds., Interdisciplinary Perspectives on Trust: Towards Theoretical and Methodological Integration, 17-47. New York: Springer.

Ridgeway, G. (2018) 'Policing in the Era of Big Data', Annual Review of Criminology 1(1): 401-419. Roché, S. and Roux, G. (2017), 'The "Silver Bullet" to Good Policing: a Mirage: An Analysis of the Effects of Political Ideology and Ethnic Identity on Procedural Justice', Policing: an International Journal, 40/3: 514-528.

Sakiyama, M., Miethe, T., Lieberman, J. et al. (2017) 'Big hover or big brother? Public attitudes about drone usage in domestic policing activities', Security Journal 30(4): 1027-1044.

St Louis, E., Saulnier, A and Walby, K. (2019), 'Police use of body worn cameras: Challenges to visibility, procedural justice and legitimacy', Surveillance and Society 17(3/4): 305-321.

Siegrist, M., Cousin, M. E., Kastenholz, H. and Wiek, A. (2007), 'Public Acceptance of Nanotechnology Foods and Food Packaging: The Influence of Affect and Trust', Appetite, 49/2: 459-466.

Slovic, P., Finucane, M., Peters, E. and MacGregor, D. G. (2002), 'Rational Actors or Rational Fools: Implications of the Affect Heuristic for Behavioral Economics', The Journal of SocioEconomics, 31/4: 329-342.

Slovic, P., Finucane, M., Peters, E. and MacGregor, D. G. (2004), 'Risk as Analysis and Risk as Feelings: Some Thoughts About Affect, Reason, Risk, and Rationality', Risk Analysis, 24/2: 311-322.

Sunshine, J. and Tyler, T. R. (2003), 'The Role of Procedural Justice and Legitimacy in Shaping Public Support for Policing', Law \& Society Review, 37/3: 513-548.

Trinkner, R., Jackson, J. and Tyler, T. R. (2018), 'Bounded Authority: Expanding “Appropriate” Police Behaviour Beyond Procedural Justice', Law and Human Behavior, 42/3: 280-293.

Tyler, T. R. (2013), Why People Cooperate: The Role of Social Motivations. Princeton: Princeton University Press.

Tyler, T. R. and Huo, Y. (2002), Trust in the Law: Encouraging Public Cooperation with the Police and Courts. New York: Russell Sage Foundation.

Tyler, T. R. and Jackson, J. (2014), 'Popular Legitimacy and the Exercise of Legal Authority: Motivating Compliance, Cooperation, and Engagement', Psychology, Public Policy, and Law, 20/1: 78-95.

Yesberg, J. A. and Bradford, B. (2018), 'Affect and Trust as Predictors of Public Support for Armed Police: Evidence from London’, Policing \& Society. Advanced online publication. 
Figure 1: Conceptual Map

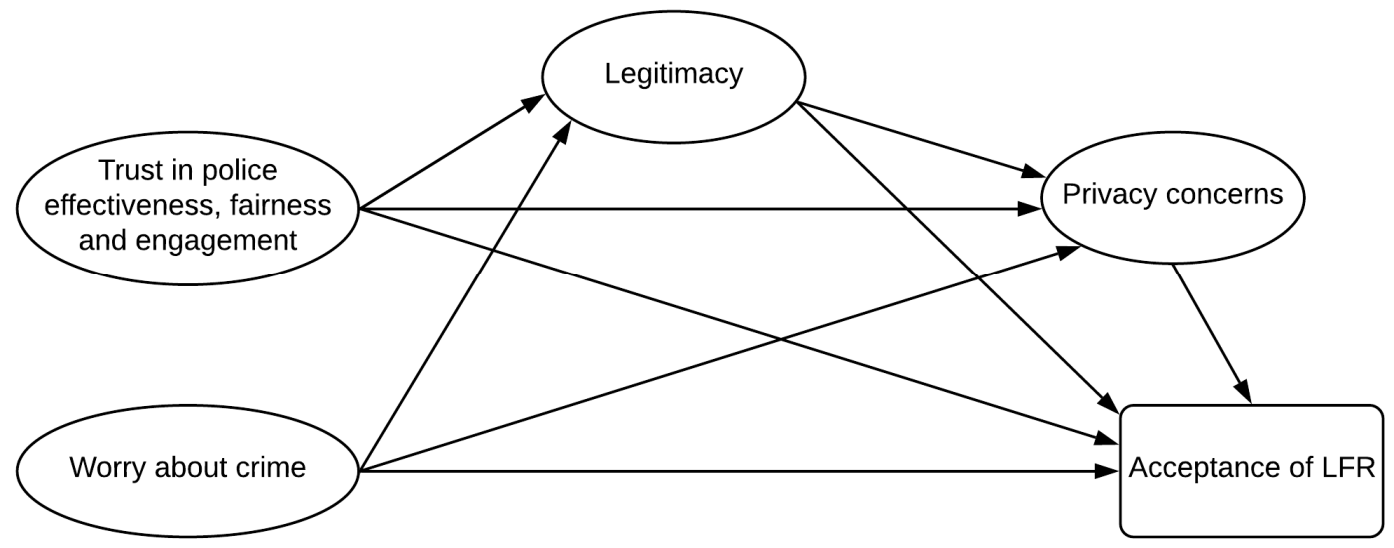


Figure 2: Results from SEM, binary acceptability measure

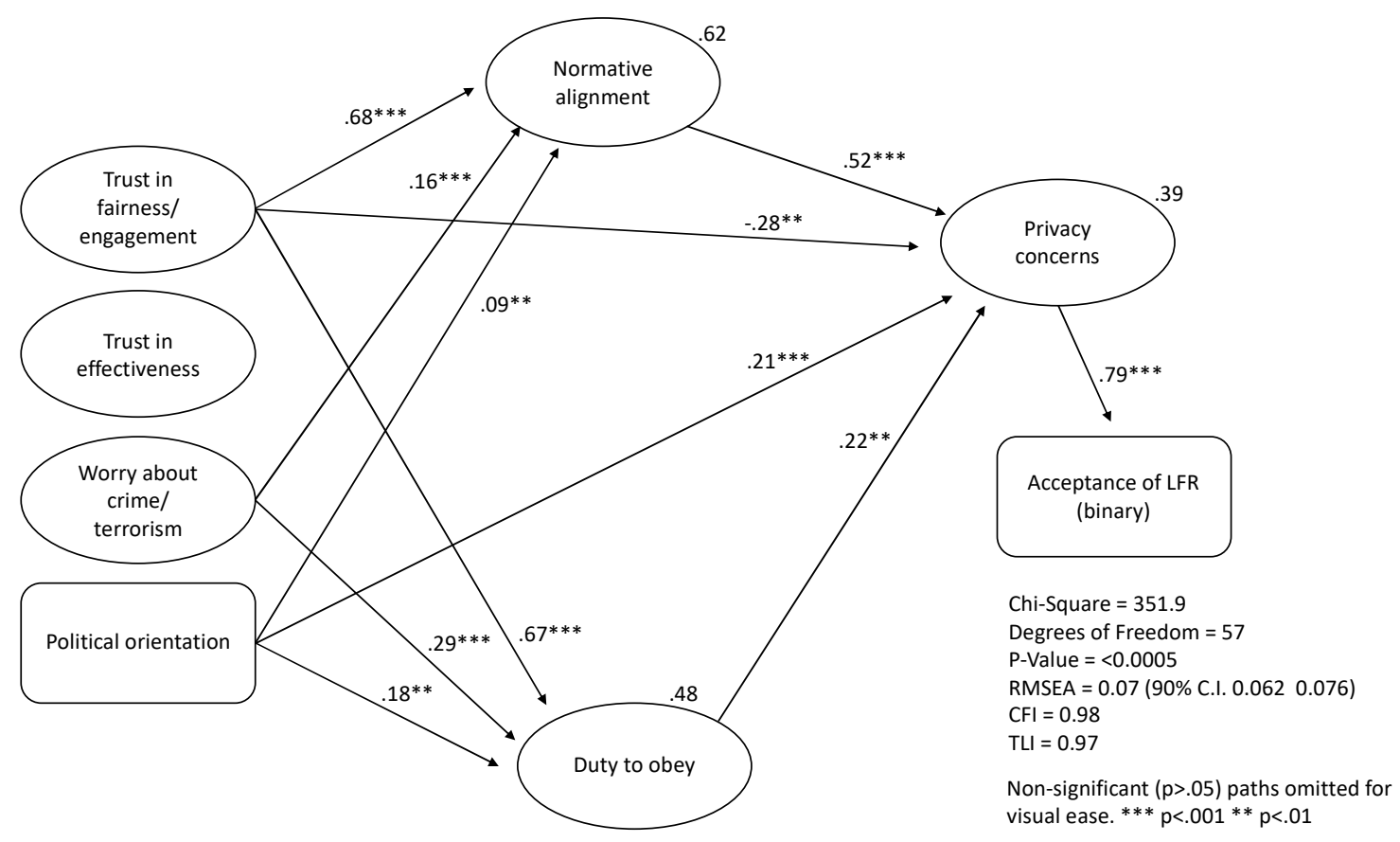


Figure 3: Results from SEM, sum score acceptability measure

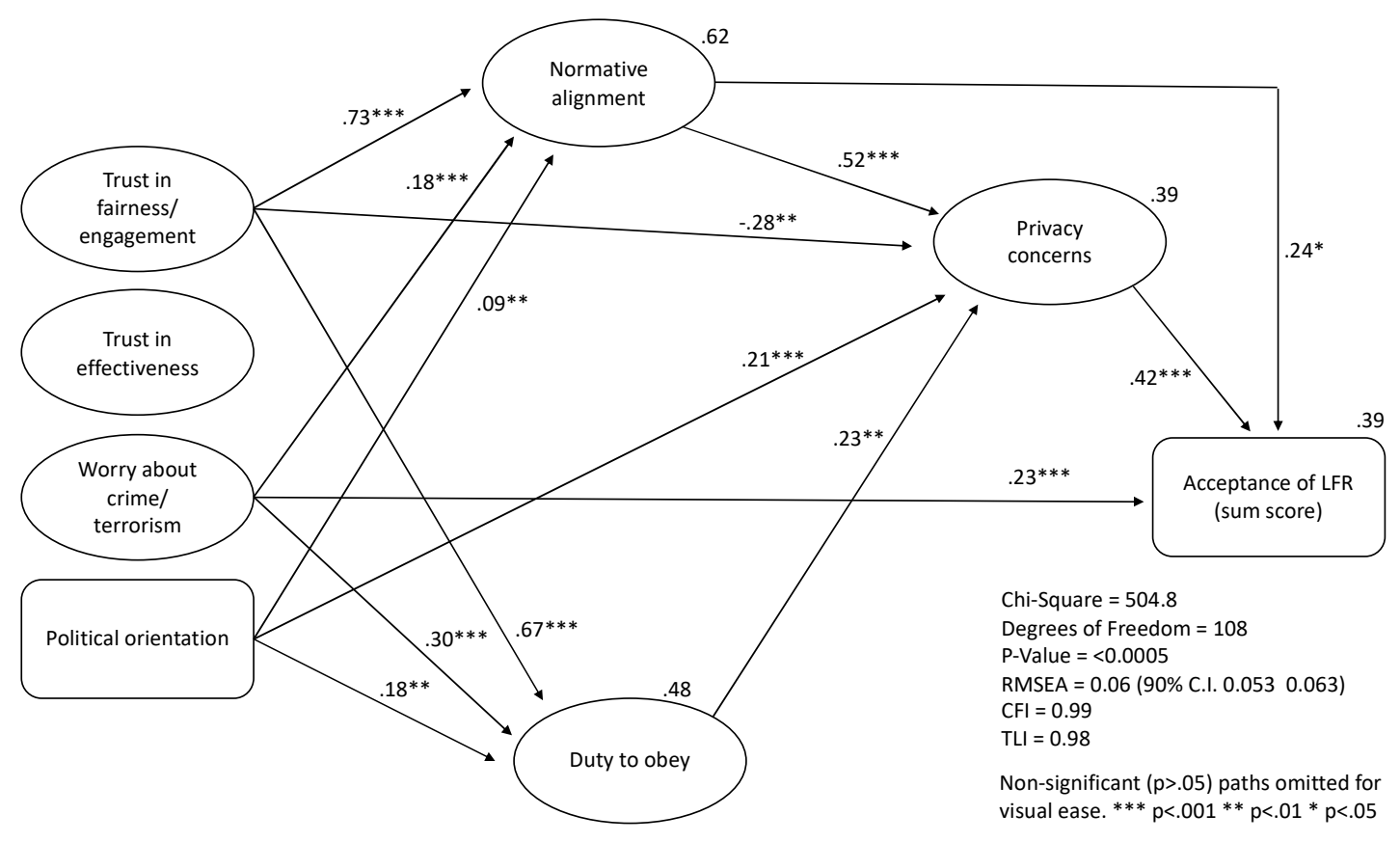


Table 1: Views of LFR on presentation of vignette

Do you agree or disagree with each of the following statements about LFR?

\begin{tabular}{lcc} 
& \multicolumn{2}{c}{ Percentage agreeing } \\
\hline & Discard & Keep \\
\hline It invades people's privacy & 40 & 42 \\
It is wrong for police to collect personal data in this & 35 & 36 \\
manner from people who have not committed a crime & 35 & 36 \\
It makes me feel worried about my privacy & 45 & 47 \\
It will lead to certain groups' personal information being & 51 & 50 \\
collected more often than others & 76 & 74 \\
It makes me feel safer & 19 & 19 \\
It will make it easier for the police to catch criminals & & \\
I would stay away from events where I know LFR would \\
be used
\end{tabular}

Note: Percentages calculated with missing values excluded

Weighted data 
Table 2: Acceptability of LFR by socio-demographic characteristics

\begin{tabular}{|c|c|c|}
\hline & $\%$ & $\begin{array}{c}\mathrm{n}(=100 \%) \\
\text { (unweighted) }\end{array}$ \\
\hline \multicolumn{3}{|l|}{ Gender } \\
\hline Female & 57 & 616 \\
\hline Male & 57 & 476 \\
\hline \multicolumn{3}{|l|}{ Age } \\
\hline $16-24$ & 45 & 137 \\
\hline $25-39$ & 48 & 311 \\
\hline $40-54$ & 62 & 295 \\
\hline $55+$ & 66 & 349 \\
\hline \multicolumn{3}{|c|}{ Ethnic group } \\
\hline Asian & 44 & 118 \\
\hline Black & 36 & 53 \\
\hline Mixed & 65 & 51 \\
\hline White & 63 & 801 \\
\hline Other1 & 24 & 24 \\
\hline \multicolumn{3}{|c|}{ Country of birth } \\
\hline UK & 58 & 852 \\
\hline Outside UK & 55 & 212 \\
\hline \multicolumn{3}{|l|}{ Social class } \\
\hline $\mathrm{ABC} 1$ & 57 & 698 \\
\hline C2DE & 57 & 394 \\
\hline \multicolumn{3}{|c|}{ Recent victim of crime } \\
\hline No & 56 & 884 \\
\hline Yes & 60 & 178 \\
\hline
\end{tabular}

Notes: The measure of acceptabiliy collapses across the 'discard' and 'retain' conditions.

Percentages calculated with missing values excluded.

Data for the category Ethnic group - other should be treated due to small sample size.

Weighted data. 
Table 3: Approval for use of LFR in different scenarios

In principle, to what extent do you agree or disagree it would be acceptable for the Metropolitan Police to use LFR ...

Percentage agreeing it is acceptable

To scan crowds at train stations to identify potential terrorists 83

Inside a ticketed event at a major arena (e.g. a sport/ music event) to identify potential 82 terrorists

To scan crowds at train stations to identify people wanted by the police for serious violent crimes

Inside a ticketed event at a major arena (e.g. a sport/ music event) to identify people wanted by the police for serious violent crimes

Inside a ticketed event at a major arena (e.g. a sport/ music event) to identify people wanted by the police for minor crimes

To scan crowds at train stations to identify people wanted by the police for minor crimes

Inside a ticketed event at a major arena (e.g. a sport/ music event) to identify people wanted for nuisance behaviour

To scan crowds at train stations to identify people wanted for nuisance behaviour

Note: Percentages calculated with missing values excluded

Weighted data 
Table 4: Direct, indirect and total effects calculated from SEM shown in Figure 2

Standardized coefficients

Privacy concerns Acceptance of LFR

Worry about crime

Direct

Total indirect

Total

$-0.06-0.06$

$.15 * * * \quad 0.09 *$

Trust in fairness/engagement

Direct

Total indirect

$.09 *$

$0.16 * *$

Total

$-0.28 * *$

$-0.004$

$0.54 * * *$

$0.24 * *$

$0.26 * *$

$0.24 *$

Trust in effectiveness

Direct

Total indirect

0.01

0.11

Total

0.02

0.01

0.02

0.13

Normative alignment

Direct

Total indirect

Total

0.01

Duty to obey

Direct

. $0.41 * * *$

Total indirect

. 0.04

Total

$0.18 * *$ 


\section{Appendix Table 1: Latent constructs and measures}

Results from a six factor solution with no cross-loadings

\begin{tabular}{|c|c|c|}
\hline & $\begin{array}{r}\text { Factor } \\
\text { loading }\end{array}$ & $\mathrm{R}^{2}$ \\
\hline \multicolumn{3}{|l|}{$\begin{array}{l}\text { Privacy Concerns ("Do you agree or disagree with each of the following statements about } \\
\text { LFR?" High = disagree) }\end{array}$} \\
\hline It invades people's privacy & 0.94 & 0.88 \\
\hline $\begin{array}{l}\text { It is wrong for police to collect personal data in this manner from people who have not } \\
\text { committed a crime }\end{array}$ & 0.91 & 0.82 \\
\hline It makes me feel worried about my privacy & 0.91 & 0.83 \\
\hline It will lead to certain groups' personal information being collected more often than others & 0.65 & 0.42 \\
\hline \multicolumn{3}{|l|}{ Worry about crime ("How worried are you about ..." High = more) } \\
\hline Crime and anti-social behaviour_in your local area & 0.92 & 0.85 \\
\hline A terrorist attack in London & 0.50 & 0.25 \\
\hline \multicolumn{3}{|l|}{$\begin{array}{l}\text { Trust in police fairness/engagement ("To what extent do you agree or disagree with the } \\
\text { following statements about police in your area?" High = agree) }\end{array}$} \\
\hline They would treat you with respect if you had contact with them for any reason & 0.88 & 0.77 \\
\hline They are dealing with the things that matter to people in this community & 0.74 & 0.55 \\
\hline The police in this area listen to the concerns of local people & 0.83 & 0.69 \\
\hline \multicolumn{3}{|l|}{$\begin{array}{l}\text { Trust in police effectiveness ("How well do you think the Metropolitan Police ..." High = } \\
\text { better) }\end{array}$} \\
\hline Prevents terrorism & 0.62 & 0.39 \\
\hline Responds to emergencies promptly & 0.74 & 0.55 \\
\hline Provides a visible patrolling presence & 0.66 & 0.69 \\
\hline \multicolumn{3}{|l|}{$\begin{array}{l}\text { Normative alignment ("To what extent do you agree or disagree with the following } \\
\text { statements?" High = agree) }\end{array}$} \\
\hline The police stand up for values that are important to people like me & 0.89 & 0.79 \\
\hline $\begin{array}{l}\text { The police usually act in ways that are consistent with my own ideas about what is right and } \\
\text { wrong }\end{array}$ & 0.89 & 0.79 \\
\hline \multicolumn{3}{|l|}{$\begin{array}{l}\text { Duty to obey ("To what extent do you agree or disagree with the following statements?" High = } \\
\text { agree) }\end{array}$} \\
\hline It is my duty to support the decisions made by the police even when I disagree with them & 0.82 & 0.67 \\
\hline It is my duty to do what the police tell me even if I don't understand or agree with the reasons & 0.79 & 0.63 \\
\hline \multicolumn{3}{|l|}{ Fit Statistics } \\
\hline Chi square & 425.6 & \\
\hline Degrees of Freedom & 88 & \\
\hline P-value & $<.0005$ & \\
\hline RMSEA (Root Mean Square Error Of Approximation) & 0.06 & \\
\hline CFI & 0.99 & \\
\hline TLI & 0.98 & \\
\hline
\end{tabular}

Appendix Table 2: Correlation matrix

$\begin{array}{lllllll}1 & 2 & 3 & 4 & 5 & 6 & 7\end{array}$

Trust in police effectiveness (1)

Trust in police fairness/engagement (2)

1

$0.78 \quad 1$


Worry about crime (3)

Duty to obey (4)

Normative alignment (5)

Political orientation (6)

\begin{tabular}{rrrrrrrr}
-0.20 & -0.31 & 1 & & & & \\
0.58 & 0.35 & 0.22 & 1 & & & \\
0.76 & 0.59 & 0.01 & 0.78 & 1 & & \\
0.15 & 0.03 & 0.19 & 0.33 & 0.23 & 1 & \\
0.30 & 0.20 & 0.09 & 0.53 & 0.54 & 0.35 & 1 \\
\hline
\end{tabular}

Privacy concerns (7) 